\title{
Analisis Pengendalian Mutu Produk Koran Dalam Upaya mengendalikan Tingkat Kerusakan Produk
}

\author{
Sri Meutia ${ }^{1^{*}}$ Syamsul Bahri ${ }^{2}$ Dirahayu ${ }^{3}$ \\ ${ }^{1} J u r u s a n$ Teknik Industri, Fakultas Teknik, Universitas Malikussaleh, Aceh-Indonesia \\ *Corresponding Author: ${ }^{1}$ srimeutia_mti@yahoo.co.id
}

\begin{abstract}
Abstrak - PT. Serambi Indonesia Biro Lhokseumawe adalah perusahaan yang bergerak dalam bidang percetakan dan penerbitan dengan produk utamanya yaitu Koran Serambi yang merupakan Koran andalan masyarakat Aceh. Penelitian ini bertujuan untuk mengetahui bagaimana pelaksanaan pengendalian kualitas menggunakan alat bantu statistik bermanfaat dalam upaya mengendalikan tingkat kerusakan produk di perusahaan. Analisis pengendalian kualitas dilakukan menggunakan alat bantu statistik berupa histogram, peta kendali $p$, dan diagram sebab-akibat. Hasil analisis peta kendali $p$ menunjukkan bahwa proses berada dalam keadaan tidak terkendali atau masih mengalami penyimpangan. Hal ini dapat dilihat pada grafik kendali dimana titik berfluktuasi sangat tinggi dan tidak beraturan, serta banyak yang keluar dari batas kendali. Berdasarkan diagram pareto, prioritas perbaikan yang perlu dilakukan adalah untuk jenis kerusakan yang dominan yaitu warna kabur (28,31\%), tidak register (19,79\%) dan terpotong (19,50\%). Dari analisis diagram sebab akibat dapat diketahui faktor penyebab misdruk berasal dari faktor manusia/ pekerja, mesin produksi, metode kerja, material/ bahan baku dan lingkungan kerja, sehingga perusahaan dapat mengambil tindakan pencegahan serta perbaikan untuk menekan tingkat misdruk dan meningkatkan kualitas produk. Copyright (02018 Department of industrial engineering. All rights reserved.
\end{abstract}

Kata Kunci: Pengendalian Kulitas, Alat Bantu Statistik, Misdruk, Register

\section{Pendahuluan}

Perkembangan teknologi akhir-akhir ini berjalan dengan pesat. Hal ini dapat dirasakan diberbagai kegiatan dan bidang kehidupan, khususnya dibidang industri percetakan. Perubahan teknologi yang dipergunakan dapat menimbulkan perubahan dari komponen input yang digunakan serta output yang dihasilkan.

Kualitas dari produk yang dihasilkan oleh perusahaan di tentukan berdasarkan ukuran-ukuran dan karakteristik tertentu. Suatu produk dikatakan berkuallitas baik apabila dapat memenuhi kebutuhan dan keinginan pelanggan atau dapat diterima pelanggan sebagai batas spesifikasi, dan proses yang baik yang diberikan oleh produsen sebagai batas control. Produk yang berkualitas akan memberi keuntungan bisnis bagi produsennya dan dapat memberi kepuasan bagi konsumen serta menghindari banyaknya keluhan para pelanggan yang menerima produk.

PT. Serambi Indonesia Biro Lhokseumawe terletak di jalan Medan- Banda Aceh Cunda Kota Lhokseumawe yang bergerak dibidang industri percetakan dengan hasil produksi utamanya berupa koran harian, seperti koran serambi dan prohaba. Dalam setiap aktivitas produksi selalu berusaha untuk menghasilkan produk yang berkualitas baik dengan menerapkan standar produksi dengan menetapkan standar yang tinggi. Rata-rata produksi koran setiap bulannya yaitu mencapai 61.723 ton, namun dalam proses produksi masih banyak terjadi misdruk yang melebihi batas minimum dengan rata-rata 2.506 ton.

Salah satu aktifitas dalam menciptakan kualitas agar sesuai standar adalah dengan menerapkan sistem pengendalian kualitas yang tepat, mempunyai tujuan dan tahap yang jelas serta memberika inovasi dalam 
melakukan pencegahan dan menyelesaikan masalah-masalah yang dihadapi perusahaan. Penurunan produksi akibat kerusakan (0,5 ton / bulan) mengakibatkan perusahaan merugi dan selama ini perusahan belum optimal dalam pengendalian kualitas produksi maka peneliti ingin melakukan" Analisis Pengendalian Mutu Produk Koran di PT. Serambi Indonesia Biro Lhokseumawe Dalam Upaya Mengendalikan Tingkat Kerusakan Produk Menggunakan Alat Bantu Statistik”

\section{$2 \quad$ Landasan Teori}

Pengendalian kualitas statistik (statistical quality control) adalah alat yang sangat berguna dalam membuat produk sesuai dengan spesifikasi sejak dari awal proses hingga akhir proses $[1,2,3]$. Pengendalian kualitas statistik dilakukan dengan cara, peta kendali $\mathrm{p}$ (control chart) dan diagram tulang ikan (fishbone chart).

Peta kendali $\mathrm{p}$ adalah salah satu peta kendali yang digunakan dalam pengendalian kualitas secara atribut, yaitu untuk mengetahui cacat (defect) atau kecacatan (defective) pada produk yang dihasilkan [4,5]. Peta kendali $\mathrm{p}$ memiliki manfaat membantu pengawasan atau pengendalian proses produksi, sehingga dapat memberikan informasi kapan dan dimana waktu yang tepat untuk melakukan perbaikan terhadap kualitas.

Penggunaan peta kendali $\mathrm{p}$ ini adalah dikarenakan pengendalian kualitas yang dilakukan bersifat atribut, serta data yang diperoleh yang dijadikan sampel pengamatan tidak tetap dan produk yang mengalami kerusakan (misdruk) tersebut tidak dapat diperbaiki lagi sehingga harus di reject dengan cara di lebur atau di daur ulang. Adapun langkah-langkah dalam membuat peta kendali $p$ sebagai berikut:

a. Menghitung Prosentase Kerusakan yaitu:

$$
p=\frac{n p}{n} \text {. }
$$

b. Menghitung garis pusat/Central Line $(\mathrm{CL})$

Garis pusat merupakan rata-rata kerusakan produk (p).

$$
C L=p=\quad \frac{\sum n p}{\sum n}
$$

c. Menghitung batas kendali atas atau Upper Control Limit (UCL)

Untuk menghitung batas kendali atas atau UCL dilakukan dengan rumus:

$$
U C L=p+\quad 3 \sqrt{\frac{P(1-P)}{n}}
$$

d. Menghitung batas kendali bawah atau Lower Control Limit (LCL)

Untuk menghitung batas kendali bawah atau LCL dilakukan dengan rumus:

$$
L C L=p-\quad 3 \sqrt{\frac{P(1-P)}{n}} .
$$

Diagram sebab akibat (cause effect diagram) disebut juga diagram tulang ikan (fishbone chart) untuk merumuskan penyebab cacat yang terjadi pada produk yang diamati berguna untuk melihat faktor-faktor utama yang berpengaruh pada kualitas dan mempunyai akibat pada masalah yang kita pelajari, selain itu kita dapat melihat faktor-faktor yang lebih terperinci yang berpengaruh dan mempunyai akibat pada faktor utama yang padat kita lihat pada panah-panah berbentuk tulang ikan pada diagram fishbone $[6,7,8]$.

Faktor-faktor penyebab utama dalam diagram sebab akibat (cause effect diagram) dapat dikelompokkan dalam: 1). Material (bahan baku); 2). Machine (mesin); 3). Man (tenaga kerja); 4). Method (metode); dan 5). Environment (lingkungan).

\section{Metodologi Penelitian}

\subsection{Lokasi dan Waktu Penelitian}

Penelitian ini dilakukan di PT. Serambi Indonesia Biro Lhokseumawe yang memproduksi Koran berupa Koran Serambi dan Prohaba terletak di Jalan. MedanBanda Aceh Cunda kecamatan Muara Satu Kota Lhokseumawe. Penelitian dilakukan pada bulan Februari 2016 hingga selesai. Objek penelitian yang diamati adalah kualitas percetakan Koran dengan melihat sistem percetakan dan hasil percetakan selama ini.

\subsection{Objek Penelitian}

Objek penelitian adalah pengendalian tingkat kerusakan produk koran di PT Serambi Indonesia

\subsection{Sumber Data yang Digunakan}

Sumber data yang digunakan terdiri dari:

1. Data primer adalah data yang dikumpulkan secara langsung dari objek penelitian, Data primer yang dibutuhkan dalam penelitian ini:
a. Data jam perbaikan mesin
b. Jam perbaikan

2. Data sekunder adalah data yang diperoleh dari perusahaan. Data sekunder yang dibutuhkan dalam penelitian ini:
a. Data jumlah produk
b. Data jumlah produk cacat

\section{Hasil dan Pembahasan}

Dalam melakukan pengendalian kualitas secara statistik, langkah pertama yang akan dilakukan adalah membuat check sheet. Check sheet berguna untuk mempermudah proses pengumpulan data serta analisis. Selain itu pula berguna untuk mengetahui area permasalahan berdasarkan frekuensi dari jenis atau penyebab dan mengambil keputusan untuk melakukan perbaikan atau tidak.

Sebagai catatan bahwa pada 1 eksemplar koran hasil produksi, bisa saja terdapat tidak hanya satu jenis 
kerusakan (misdruk), akan tetapi bisa lebih dari satu macam. Oleh karena itu, jenis kerusakan yang dicatat oleh bagian produksi adalah jenis kerusakan yang paling dominan.

Tabel 1 Data Produksi PT. Serambi Indonesia Biro Lhokseumawe Tahun2015-2016

\begin{tabular}{|c|c|c|c|c|c|c|c|c|}
\hline \multirow[b]{2}{*}{ Bulan } & \multirow[b]{2}{*}{$\begin{array}{c}\text { Jumlah } \\
\text { Produksi } \\
\text { Koran/Bulan } \\
\text { (Lembar) }\end{array}$} & \multicolumn{5}{|c|}{ Jenis Misdruks } & \multirow[b]{2}{*}{$\begin{array}{l}\text { Jumlah } \\
\text { Miscruss } \\
\text { (Lembar) }\end{array}$} & \multirow[b]{2}{*}{$\begin{array}{l}\text { Persentas } \\
\text { Misdruk } \\
(\%)\end{array}$} \\
\hline & & $\begin{array}{l}\text { Kotor } \\
\text { (Lembar) }\end{array}$ & $\begin{array}{c}\text { Warna } \\
\text { Kabur } \\
\text { (Lembar) }\end{array}$ & $\begin{array}{l}\text { Tidak } \\
\text { Register } \\
\text { (Lembar) }\end{array}$ & $\begin{array}{l}\text { Lipatan } \\
\text { Tidak } \\
\text { Simertis } \\
\text { (Lembar) }\end{array}$ & $\begin{array}{l}\text { Terpotong } \\
\text { (Lembar) }\end{array}$ & & \\
\hline April & 8,908 & 16,079 & 1,289 & 1,398 & 1,289 & 16,209 & 36,264 & 40 \\
\hline Mei & $8,768,509$ & 21,500 & 3,890 & 1,219 & 1,259 & & 46,788 & 53 \\
\hline Juni & 9,628 & & 6,491 & 1,040 & 1,229 & & $\begin{array}{l}57,312 \\
68936\end{array}$ & 59 \\
\hline & $\begin{array}{l}11,488 \\
1134\end{array}$ & $\begin{array}{l}32,342 \\
37763\end{array}$ & $\begin{array}{l}9,092 \\
11693\end{array}$ & $\begin{array}{l}1,861 \\
1,682\end{array}$ & $\begin{array}{l}1,199 \\
1,169\end{array}$ & $\begin{aligned} 24,342 \\
27,053\end{aligned}$ & $\begin{array}{l}68,836 \\
79360\end{array}$ & $\begin{array}{l}59 \\
69\end{array}$ \\
\hline $\begin{array}{l}\text { Agusustus } \\
\text { September }\end{array}$ & $\begin{array}{l}11,342,236 \\
10,208,145\end{array}$ & $\begin{array}{l}37,733 \\
43,184\end{array}$ & $\begin{array}{l}11,693 \\
11,294\end{array}$ & $\begin{array}{l}1,682 \\
1,503\end{array}$ & $\begin{array}{l}1,169 \\
1,139\end{array}$ & $\begin{array}{l}27,0,03 \\
2,964\end{array}$ & $\begin{array}{l}79,380 \\
8688\end{array}$ & $\begin{array}{l}69 \\
85\end{array}$ \\
\hline $\begin{array}{l}\text { Oopember } \\
\text { Oktober }\end{array}$ & $\begin{array}{l}10,708 \\
8,768\end{array}$ & $\begin{array}{l}4,1,164 \\
21,600\end{array}$ & 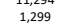 & $\begin{array}{l}1,503 \\
1,259\end{array}$ & $\begin{array}{l}1,139 \\
1,532\end{array}$ & $\begin{array}{l}29,164 \\
16,079\end{array}$ & $\begin{array}{l}8,0,844 \\
41,769\end{array}$ & $\begin{array}{l}83 \\
65\end{array}$ \\
\hline Novem & $9,628,418$ & 26,22 & 3,792 & 1,229 & 1, & 21 & 54,140 & 75 \\
\hline Desember & 11,488 & 32,3 & & & & 24 & 68,836 & 59 \\
\hline & 11,48 & & & & 1,219 & 26 & 68,574 & \\
\hline Februa & 11, & & & 69 & 40 & 42 & $\begin{array}{l}81,806 \\
0,700\end{array}$ & 65 \\
\hline $\begin{array}{l}\text { Maret } \\
\text { Aaril }\end{array}$ & $\begin{array}{l}11,438,327 \\
11,439,236\end{array}$ & $\begin{array}{l}43,274 \\
43,184\end{array}$ & $\begin{array}{l}13,693 \\
15,698\end{array}$ & $\begin{array}{l}1,179 \\
1,129\end{array}$ & $\begin{array}{l}1,661 \\
1,682\end{array}$ & $\begin{array}{l}37,7,73 \\
43,184\end{array}$ & $\begin{array}{l}97,700 \\
104,877\end{array}$ & $\begin{array}{l}55 \\
53\end{array}$ \\
\hline
\end{tabular}

Untuk memudahkan dalam melihat lebih jelas misdruk yang terjadi sesuai dengan Tabel 1 diatas, langkah selanjutnya membuat histogram data produk misdruk disajikan dalam bentuk grafik Histogram jenis misdruk dapat dilihat pada Gambar 1.

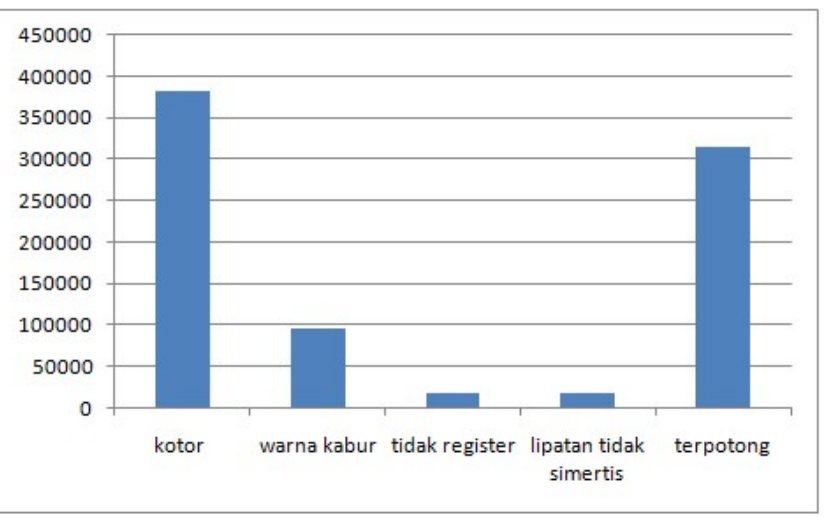

Gambar 1 Grafik Histrogram Jenis Misdruk

Dari gambar diatas dapat dilihat bahwa kerusakan koran terbanyak di sebabkan koran kotor sebanyak 382.073, kemudain Koran terpotong sebnyak 315.708, warna kabur sebnyak 94716, terlipat tidak simetris dan tidak register. Kerusakan paling sedikit yaitu lipatan tidak simetris sebanyak 16.016 dan tidak register sebnyak 15.867.

\subsection{Peta Kendali P}

Dari tabel 4.1 dapat dilihat terdapat jumlah misdruk yang melebihi batas toleransi misdruk yang ditetapkan perusahaan sebesar $6 \%$ per produksi. Oleh karena itu, selanjutnya akan dianalisis kembali untuk mengetahui sejauh mana misdruk yang terjadi masih dalam batas kendali statistik melalui grafik kendali. Peta kendali $p$ mempunyai manfaat untuk membantu pengendalian kualitas produksi serta dapat memberikan informasi mengenai kapan dan dimana perusahaan harus melakukan perbaikan kualitas.

Adapun langkah-langkah untuk membuat peta kendali $p$ adalah:

1. Menghitung Prosentase Kerusakan $P=\frac{n p}{n}$

Perhitungan mulai dari bulan april 2015 hingga april 2016. Maka perhitungan persentase kerusakan adalah sebagai berikut:

\begin{tabular}{|c|c|}
\hline Bulan April & $P=\frac{n p}{n}=\frac{36.264}{8.908 .600}=0,40$ \\
\hline Bulan Mei & $=\frac{n p}{n}=\frac{46.788}{8.768 .509}=0,53$ \\
\hline Bulan Juni & $P=\frac{n p}{n}=\frac{57 \cdot 312}{9 \cdot 628 \cdot 418}=0,59$ \\
\hline Bulan Juli & $\frac{n p}{n}=\frac{68.836}{11.488 .327}=0,59$ \\
\hline Bulan Agustus & $\frac{n p}{n}=\frac{79.360}{11.342 .236}=0,69$ \\
\hline Bulan Sept & $P=\frac{n p}{n}=\frac{86 \cdot 884}{10 \cdot 208 \cdot 145}=0,85$ \\
\hline Bulan Oktober & $\frac{n p}{n}=\frac{41 \cdot 769}{8 \cdot 768 \cdot 509}=0,65$ \\
\hline Bulan November & $\frac{n p}{n}=\frac{54 \cdot 140}{9 \cdot 628.418}=0,75$ \\
\hline Bulan Desember & $\frac{n p}{n}=\frac{68.836}{11 \cdot 488.327}=0,59$ \\
\hline Bulan Januari & $\frac{n p}{n}=\frac{68 \cdot 574}{11 \cdot 488 \cdot 327}=0,63$ \\
\hline Bulan Februari & $\frac{n p}{n}=\frac{81 \cdot 806}{11 \cdot 388 \cdot 236}=0,65$ \\
\hline Maret & $\frac{n p}{n}=\frac{97 \cdot 770}{11 \cdot 488 \cdot 327}=0,65$ \\
\hline$A$ & $P=\frac{n p}{n}=\frac{104 \cdot 877}{11 \cdot 349 \cdot 236}=0,53$ \\
\hline
\end{tabular}

2. Menghitung garis pusat/ Central Line (CL)

Garis pusat yang merupakan rata-rata kerusakan produk $(p)$.

$$
\begin{aligned}
& \mathrm{CL}=\mathrm{P}=\frac{\sum n p}{\sum n} \\
& \mathrm{CL}=\mathrm{P}=\frac{375 \cdot 444}{64 \cdot 350 \cdot 235}=0,58
\end{aligned}
$$

3. Menghitung batas kendali atas atau Upper Control Limit (UCL)

Untuk menghitung batas kendali atas atau UCL dilakukan dengan rumus:

$$
\mathrm{UCL}=\mathrm{P}+3 \frac{\sqrt{P(1-P)}}{n}
$$

Perhitungan mulai dari bulan April 2015 hingga April 2016.

$$
\begin{array}{ll}
\text { Bulan April } & =\mathrm{P}+3 \frac{\sqrt{P(1-P)}}{n} \\
& =0,62+3 \frac{\sqrt{0,62(1-0,62)}}{36.264}=0,69 \\
\text { Bulan Mei } & =\mathrm{P}+3 \frac{\sqrt{P(1-P)}}{n} \\
& =0,62+3 \frac{\sqrt{0,62(1-0,62)}}{46.788}=0,69
\end{array}
$$




$$
\begin{aligned}
& \text { Bulan Juni } \quad=\mathrm{P}+3 \frac{\sqrt{P(1-P)}}{n} \\
& =0,62+3 \frac{\sqrt{0,62(1-0,62)}}{57,312}=0,69 \\
& \text { Bulan Juli } \quad=\mathrm{P}+3 \frac{\sqrt{P(1-P)}}{n} \\
& =0,62+3 \frac{\sqrt{0,62(1-0,62)}}{68,836}=0,69 \\
& \text { Bulan Agustus }=\mathrm{P}+3 \frac{\sqrt{P(1-P)}}{n} \\
& =0,62+3 \frac{\sqrt{0,62(1-0,62)}}{79,360}=0,69 \\
& \text { Bulan September }=\mathrm{P}+3 \frac{\sqrt{P(1-P)}}{n} \\
& =0,62+3 \frac{\sqrt{0,62(1-0,62)}}{86,884}=0,69 \\
& \text { Bulan Oktober }=\mathrm{P}+3 \frac{\sqrt{P(1-P)}}{n} \\
& =0,62+3 \frac{\sqrt{0,62(1-0,62)}}{41,769}=0,69 \\
& \text { Bulan November }=\mathrm{P}+3 \frac{\sqrt{P(1-P)}}{n} \\
& =0,62+3 \frac{\sqrt{0,62(1-0,62)}}{54,140}=0,69 \\
& \text { Bulan Desember }=\mathrm{P}+3 \frac{\sqrt{P(1-P)}}{n} \\
& =0,62+3 \frac{\sqrt{0,62(1-0,62)}}{68,836}=0,69 \\
& \text { Bulan Januari } \quad=\mathrm{P}+3 \frac{\sqrt{P(1-P)}}{n} \\
& =0,62+3 \frac{\sqrt{0,62(1-0,62)}}{68,574}=0,69 \\
& \text { Bulan Februari } \quad=\mathrm{P}+3 \frac{\sqrt{P(1-P)}}{n} \\
& =0,62+3 \frac{\sqrt{0,62(1-0,62)}}{81,806}=0,69 \\
& \text { Bulan Maret } \quad=\mathrm{P}+3 \frac{\sqrt{P(1-P)}}{n} \\
& =0,62+3 \frac{\sqrt{0,62(1-0,62)}}{97,770}=0,69 \\
& \text { Bulan April } \quad=\mathrm{P}+3 \frac{\sqrt{P(1-P)}}{n} \\
& =0,62+3 \frac{\sqrt{0,62(1-0,62)}}{104,877}=0,69
\end{aligned}
$$

4. Menghitung batas kendali bawah atau Lower

Control Limit (LCL)

Untuk menghitung batas kendali bawah atau LCL dilakukan dengan rumus:

$$
\mathrm{LCL}=\mathrm{P}-3 \frac{\sqrt{P(1-P)}}{n}
$$

Perhitungan mulai dari bulan April 2015 hingga April 2016.

Bulan April

$$
=\mathrm{P}-3 \frac{\sqrt{P(1-P)}}{n}
$$$$
=0,62-3 \frac{\sqrt{0,62(1-0,62)}}{36.264}=0,47
$$

Bulan Mei

$$
=\mathrm{P}-3 \frac{\sqrt{P(1-P)}}{n}
$$

$$
\begin{aligned}
& =0,62+3 \frac{\sqrt{0,62(1-0,62)}}{46.788}=0,47 \\
& \text { Bulan Juni } \quad=\mathrm{P}-3 \frac{\sqrt{P(1-P)}}{n} \\
& =0,62+3 \frac{\sqrt{0,62(1-0,62)}}{57,312}=0,47 \\
& \text { Bulan Juli } \quad=\mathrm{P}-3 \frac{\sqrt{P(1-P)}}{n} \\
& =0,62+3 \frac{\sqrt{0,62(1-0,62)}}{68,836}=0,47 \\
& \text { Bulan Agustus }=\mathrm{P}-3 \frac{\sqrt{P(1-P)}}{n} \\
& =0,62+3 \frac{\sqrt{0,62(1-0,62)}}{79,360}=0,47 \\
& \text { Bulan September }=\mathrm{P}-3 \frac{\sqrt{P(1-P)}}{n} \\
& =0,62+3 \frac{\sqrt{0,62(1-0,62)}}{86,884}=0,47 \\
& \text { Bulan Oktober }=\mathrm{P}-3 \frac{\sqrt{P(1-P)}}{n} \\
& =0,62+3 \frac{\sqrt{0,62(1-0,62)}}{41,769}=0,47 \\
& \text { Bulan November }=\mathrm{P}-3 \frac{\sqrt{P(1-P)}}{n} \\
& =0,62+3 \frac{\sqrt{0,62(1-0,62)}}{54,140}=0,47 \\
& \text { Bulan Desember }=\mathrm{P}-3 \frac{\sqrt{P(1-P)}}{n} \\
& =0,62+3 \frac{\sqrt{0,62(1-0,62)}}{68,836}=0,47 \\
& \text { Bulan Januari LCL }=\mathrm{P}-3 \frac{\sqrt{P(1-P)}}{n} \\
& =0,62+3 \frac{\sqrt{0,62(1-0,62)}}{68,574}=0,47 \\
& \text { Bulan Februari } \quad=\mathrm{P}-3 \frac{\sqrt{P(1-P)}}{n} \\
& =0,62+3 \frac{\sqrt{0,62(1-0,62)}}{81,806}=0,47 \\
& \text { Bulan Maret } \quad=\mathrm{P}-3 \frac{\sqrt{P(1-P)}}{n} \\
& =0,62+3 \frac{\sqrt{0,62(1-0,62)}}{97,770}=0,47 \\
& \text { Bulan April } \quad=\mathrm{P}-3 \frac{\sqrt{P(1-P)}}{n} \\
& =0,62+3 \frac{\sqrt{0,62(1-0,62)}}{104,877}=0,47
\end{aligned}
$$

\subsection{Diagram Sebab Akibat (Fishbone Chart)}

Diagram sebab akibat memperlihatkan hubungan antara permasalahan yang dihadapi dengan kemungkinan penyebabnya serta faktor-faktor yang mempengaruhinya. Faktor-faktor yang mempengaruhi dan menjadi penyebab kerusakan produk secara umum dapat digolongkan sebagai berikut:

1. Man (manusia)

Para pekerja yang melakukan pekerjaan yang terlibat dalam proses produksi. 
Tabel 2 Hasil perhitungan peta kendali $P$ tahun 2015 2016

\begin{tabular}{ccccccc}
\hline Bulan & Jumlah Produksi & Mumlah & Proporsi & & \\
April & $8,908,600$ & 36,264 & 40 & 0.58 & 0.69 & 0.47 \\
Mei & $8,768,509$ & 46,788 & 53 & 0.58 & 0.69 & 0.47 \\
Juni & $9,628,418$ & 57,312 & 59 & 0.58 & 0.69 & 0.47 \\
Juli & $11,488,327$ & 68,836 & 59 & 0.58 & 0.69 & 0.47 \\
Agustus & $11,342,236$ & 79,360 & 69 & 0.58 & 0.69 & 0.47 \\
September & $10,208,145$ & 86,884 & 85 & 0.58 & 0.69 & 0.47 \\
Oktober & $8,768,509$ & 41,769 & 65 & 0.58 & 0.69 & 0.47 \\
Novembe & $9,628,418$ & 54,140 & 75 & 0.58 & 0.69 & 0.47 \\
Desember & $11,488,327$ & 68,836 & 59 & 0.58 & 0.69 & 0.47 \\
Januari & $11,487,327$ & 68,574 & 63 & 0.58 & 0.69 & 0.47 \\
Februari & $11,348,236$ & 81,806 & 65 & 0.58 & 0.69 & 0.47 \\
Maret & $11,488,327$ & 97,770 & 55 & 0.58 & 0.69 & 0.47 \\
April & $11,349,236$ & 104,877 & 53 & 0.58 & 0.69 & 0.47 \\
\hline
\end{tabular}

\section{Material (bahan baku)}

Segala sesuatu yang dipergunakan oleh perusahaan sebagai komponen produk yang akan diproduksi tersebut, terdiri dari bahan baku utama dan bahan baku pembantu.

3. Machine (mesin)

Mesin-mesin dan berbagai peralatan yang digunakan dalam proses produksi.

4. Methode (metode)

Instruksi kerja atau perintah kerja yang harus diikuti dalam proses produksi.

5. Environment (lingkungan)

Keadaan sekitar perusahaan yang secara langsung atau tidak langsung mempengaruhi perusahaan secara umum dan mempengaruhi proses produksi secara khusus.

Setelah diketahui jenis-jenis misdruk yang terjadi, maka perlu mengambil langkah-langkah perbaikan untuk mencegah timbulnya kerusakan yang serupa. Hal penting yang harus dilakukan dan ditelusuri adalah mencari penyebab timbulnya kerusakan tersebut. Sebagai alat bantu untuk mencari penyebab terjadinya misdruk tersebut, digunakan diagram sebab akibat atau yang disebut fishbone chart.

1. Warna Kabur

Kurang tebalnya hasil cetakan pada kertas menjadikan gambar/foto berwarna yang tercetak dikoran menjadi kabur atau ngeblur seperti samar samar/berbayang sehingga tidak terlihar jelas.

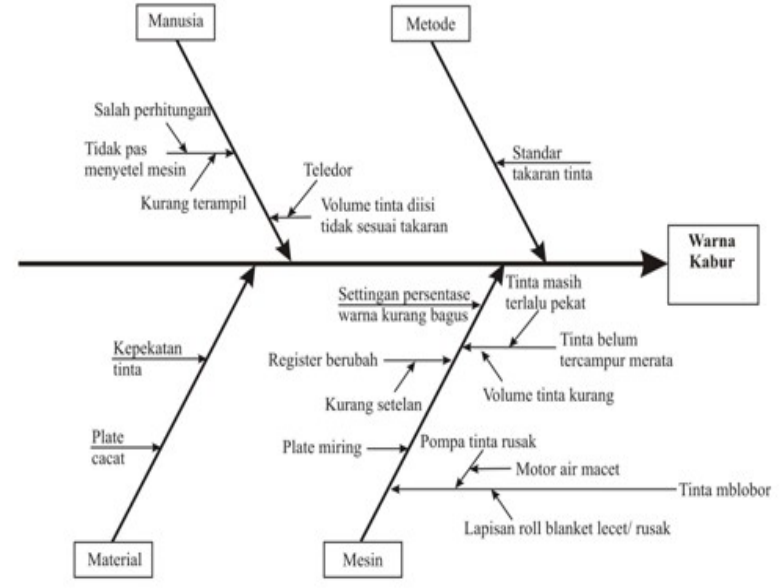

Gambar 2 Diagram Sebab Akibat Untuk Jenis Misdruk Warna Kabur

Hasil cetakan seperti ini selalu dan pasti terjadi pada saat awal produksi berlangsung. Hal ini disebabkan dari faktor-faktor sebagai berikut:

a. Faktor Mesin.

Merupakan sebab utama yang mengakibatkan kerusakan jenis ini. Hal ini disebabkan oleh:

- Setting persentase warna pada mesin yang kurang bagus, lapisan roll blanket yang lecet/rusak dan pompa tinta rusak sehingga tinta mblobor/luber.

- Kurang meratanya tinta pada tanki warna mesin cetak dikarenakan volume tinta pada tanki warna yang kurang dan tinta yang masih terlalu pekat, sehingga penyerapan warna menjadi tidak merata.

- Register yang berubah posisi dikarenakan setelan yang kurang kencang atau terlalu kendor.

- Plate untuk cetak gambar miring.

b. Faktor Manusia.

- Operator mengisi volume tinta pada tanki warna tidak sesuai takaran yang pas.

- Operator mesin yang kurang cermat dalam menyetel kekencangan mesin sehingga perputarannya dapat mengganggu kestabilan register dan plate. Hal ini disebabkan oleh operator yang mungkin belum terampil/berpengalaman dalam melakukan penyetelan yang pas dan juga karena salah perhitungan dalam menyetel kekencangan mesin. 


\section{c. Faktor Material.}

- Tingkat kepekatan tinta yang berbeda-beda disinyalir juga merupakan penyebab dari misdruk ini karena mengakibatkan percampuran untuk membuat suatu warna menjadi tidak merata.

- Adanya plate yang cacat/rusak juga dapat mengakibatkan warna menjadi kabur karena tidak dapat dibaca secara sempurna oleh mesin.

\section{d. Faktor Metode.}

Tidak adanya standar/prosedur yang jelas mengenai takaran tinta yang sesuai akan menyulitkan pekerja ketika akan mengisi tinta kedalam mesin secara tepat.

2. Tidak Register

Posisi/layout koran agak menggeser atau tidak persisi/fokus, ditandai dengan simbol yang berbentuk lingkaran dan garis silang (seperti bentuk radar) sebagai simbol acuan yang terletak pertengahan yang menjadi lipatan koran tidak berada tepat sejajar atau melebar melebihi 0,3 $\mathrm{mm}$ (batas toleransi yang ditetapkan perusahaan).

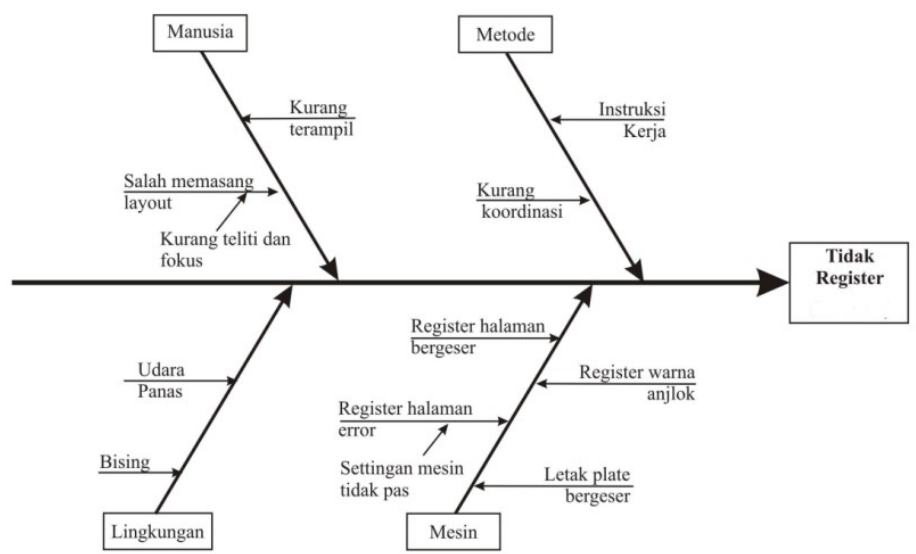

Gambar 3 Diagram Sebab Akibat Untuk Jenis Misdruk Tidak Register

Kejadian tersebut dianggap oleh perusahaan sebagai misdruk atau rusak karena layout koran juga akan ikut menggeser dan menyebabkan gambar akan terlihat kabur. Hal tersebut disebabkan oleh faktor-faktor antara lain:

a. Faktor Mesin

- Register warna yang terdapat di dalam mesin anjlok.

- Perputaran mesin yang cepat menjadikan register halaman bergeser.

- Register halaman error karena settingan mesin yang tidak pas sehingga proses cetak tidak berjalan lancar.

- Letak plate bergeser sehingga menjadikan layout koran juga ikut tergeser. b. Faktor Manusia

- Pekerja yang kurang terampil dalam melakukan setting mesin dan register.

- Kesalahan operator dalam memasang layout karena kurang teliti dan tidak fokus.

c. Faktor Metode

- Instruksi kerja yang tidak dipahami secara jelas oleh pekerja menjadikan pekerja melakukan kesalahan dan keteledoran.

- Terjadinya kesalahan kerja karena kurangnya koordinasi antara bagian perencanaan cetak koran dengan operator di lapangan mengenai penempatan layout dan settingan mesinn

d. Faktor Lingkungan

- Suhu udara yang panas menjadikan pekerja kurang nyaman dalam melakukan pekerjaannya sehingga melakukan kesalahan.

- Suara bising dari mesin sedikit banyak juga berpengaruh terhadap konsentrasi pekerja terutama sewaktu mengatur layout dan register yang membutuhkan ketelitian dan kecermatan.

3. Terpotong

Tahap pemotongan (cutting) oleh mesin dilakukan setelah proses folding atau pelipatan, yang disesuaikan dengan ukuran cut-off mesin untuk Koran Suara Merdeka.

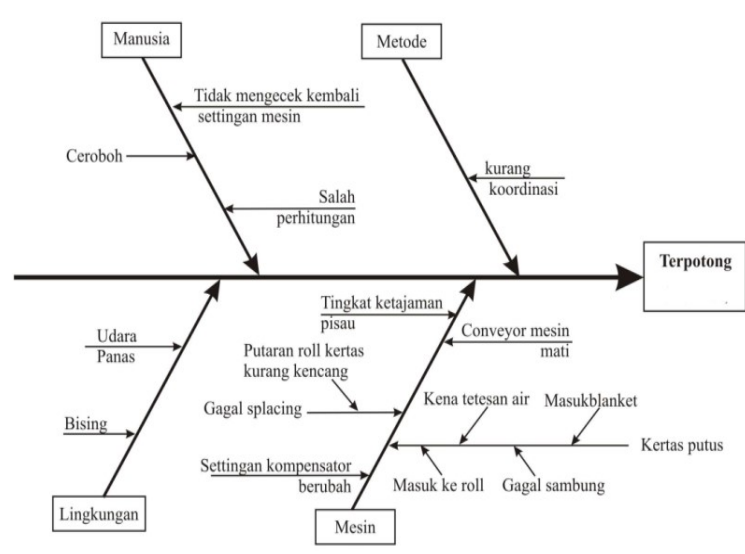

Gambar 4 Diagram Sebab Akibat Untuk Jenis Misdruk Terpotong

Apabila mesin memotong tidak tepat sesuai ukuran, maka akan menghasilkan koran yang terpotong tidak sesuai layout dimana terdapat tulisan maupun gambar yang terpotong tidak rapi. Hal ini disebabkan oleh beberapa faktor antara lain:

a. Faktor Mesin

- Settingan kompensator mesin berubah dikarenakan sebelumnya digunakan untuk mencetak buku. 
- $\quad$ Tingkat ketajaman pisau potong.

- Conveyor mesin macet/rusak akan menyebabkan aliran distribusi koran dari tahap pelipatan ke pemotongan menjadi terhambat sehingga menyebabkan banyak koran yang terpotong tidak sesuai ukuran.

- Kertas putus yang disebabkan karena terkena tetesan air, masuk ke blanket, masuk ke roll dan karena gagal sambung.

- Gagal splacing karena putaran roll kertas kurang kencang sehingga kertas yang terpotong tidak beraturan.

b. Faktor Manusia

- Operator tidak teliti dalam mengecek kembali settingan mesin setelah sebelumnya digunakan.

- Kecerobohan dari operator dalam menjalankan mesin sehingga mesin terganggu dan conveyor mesin macet.

- Kesalahan dalam memperhitungkan perputaran mesin oleh operator sehingga perputaran mesin tidak beraturan dan distribusi kertas terganggu.

c. Faktor Metode

Kurangnya koordinasi antar operator dalam menjalankan mesin menyebabkan jalannya mesin terganggu.

d. Faktor Lingkungan

- Suhu udara yang panas bisa mengganggu mood karyawan dalam bekerja sehingga banyak melakukan kecerobohan.

- Suara bising dari mesin mengurangi fokus dari para operator dalam melakukan koordinasi dalam menjalankan mesin.

\subsection{Pembahasan}

Dari hasil perhitungan analisis pengendalian mutu produk korsn di PT. Serambi Indonesia biro Lhokseumawe maka diperoleh hasil bahwa kerusakan koran terbanyak disbabkan karena koran kotor yaitu sebanyak 382.073, kemudian koran terpotong sebanyak 315.708, warna kabur sebanyak 94.716, kerusakan paling sedikit yaitu lipatan tidak simetris sebanyak 16.016, dan tidak register sebanyak 15.867.

Maka dari hasil analisis menggunkan diagram sebab akibat factor manusia dan mesin adalah hal yang sangat berpengaruh saat proses produksi berjalan, kecerobohan manusia dan kesalahan dalam memperhitungkan perputaran mesin yang sering menjadi kendala cacatnya produk.

\section{Kesimpulan}

Dari penelitian yang dilakukan untuk mengendalikan tingkat kerusakan koran di PT Serambi Indonesia, maka kesimpulan yang didapatkan adalah:

1. Jenis-jenis kerusakan atau misdruk yang sering terjadi pada produksi koran PT. serambi Indonesia biro Ihoksemawe yaitu disebabkan karena warna kabur (nge-blur) sebanyak, tidak register, serta jenis misdruk berupa rusak karena terpotong, kotor dan lipatan tidak simetris secara berturut-turut.

2. Penggunaan alat bantu statistik dengan peta kendali $\mathrm{p}$ dalam pengendalian kualitas produk dapat mengidentifikasikan bahwa ternyata kualitas produk berada di batas kendali yang seharusnya, meskipun jika berdasarkan data produksi jumlah misdruk yang terjadi sebagian besar memenuhi target dibawah 6 $\%$. Hal tersebut seperti yang ditunjukkan pada grafik kontrol yang memperlihatkan bahwasanya titik berfluktuasi sangat tinggi dan dari analisis diagram sebab akibat dapat diketahui faktor penyebab kerusakan atau misdruk dalam produksi yaitu berasal dari faktor manusia/ pekerja, mesin produksi, metode kerja, material/ bahan baku dan lingkungan kerja.

\section{Daftar Pustaka}

[1] Alisjahbana, Juita. 2005. "Evaluasi Pengendalian Kualitas Total Produk Pakaian Wanita Pada Perusahaan Konveksi." Jurnal Ventura, Vol. 8, No. 1, April 2005.

[2] Assauri, Sofjan. 1998. Manajemen Operasi Dan Produksi. Jakarta : LP FE UI

[3] Dwiwinarno, Titop. 2009. "Evaluasi Pengendalian Kualitas Pada Bagian Produksi." www.google.com. Diakses tanggal 21 Maret 2010.

[4] Hardjosoedarmo, Soewarso. 2004. Total Quality Management. Yogyakarta: Penerbit Andi.

[5] Hatani, La. 2008. "Manajemen Pengendalian Mutu Produksi Roti Melalui Pendekatan Statistical Quality Control (SQC)." Diakses 12 Maret 2010, dari www.google.com/Jurusan Manajemen FE Unhal

[6] Schroeder, Roger G. 2007. Manajemen Operasi. Jilid 2-Edisi 3. Jakarta : Penerbit Erlangga.

[7] Yamit, Zulian. 2013. Manajemen Kualitas Produk \& Jasa. Ekosinia. Jakarta.

[8] Heizer Jay, Render Barry. 2005. Operations Management. Jakarta: Salemba Empat. 